\title{
DEVELOPMENT AND USE OF THE PROGRAM OF AUTOMATIC PROBLEM SOLVING WHEN CONDUCTING PRACTICAL CLASSES IN PHYSICS AT THE UNIVERSITY
}

\author{
Alexandr Shamshin
}

The creation of a virtual educational environment, consisting of an information space that ensures the availability of unlimited educational material through communication means, a virtual or real communication channel between a student and a teacher, increases the role of self-education, the dominance of learning over teaching. Paraphrasing [1], we can say that physics is owned not by the one who knows the formulas and definitions, but by the one who, with their help, can solve physical problems (FP). Similarly to the words of E. Fermi [2]: "A person knows physics if he/she can solve problems." The ability to solve PP contributes to the concretization of students' knowledge; without it, there is a separation of theoretical, lecture, educational material from the main task of any learning process - the practical application of accumulated knowledge and skills. Solving of PP contributes to the development of mental activity, the formation of creativity, intelligence, observation, independence and accuracy, is one of the forms of repetition, control and assessment of knowledge. At the same time, it is the solution of problems that is the most difficult element of physical education, causing methodological, didactic, psychological, and mathematical difficulties.

It is known, that along with the traditional methods of solving PP: arithmetic, algebraic, geometric, graphic, experimental, since the beginning of the 2000s, information technology, computer technology, and programs - answer books have been actively used. The traditionally difficult issue of solving problems in physics requires both the improvement of classical methods and the development of new software tools for solving problems. The paper discusses the possibilities of using computers to solve various types of physical problems, the use of a site, created by the author, with considered examples of solving more than 2500 problems in physics, a developed program for automatic solution of problems in physics (APS - automatic physics solver) during practical exercises

Keywords: practical lesson, software for solving problems, examples of solving physics problems, automatic problem solving in physics

How to cite:

Shamshin, A. (2021). Development and use of the program of automatic problem solving when conducting practical classes in physics at the university. ScienceRise: Pedagogical Education, 5 (44), 23-29. doi: http://doi.org/10.15587/2519-4984.2021.241236

(C) The Author(s) 2021

This is an open access article under the Creative Commons CC BY license hydrate

\section{Introduction}

Digital pedagogy requires the improvement of the methodological system of computer training [3]. Knowledge has a practical value when a student can use it, has the skills and abilities to apply the knowledge gained, for example, when solving problems in physics. The acquisition of problem-solving skills contributes to mental development, formulates the composition of mental operations and skills, which, in turn, develops creative thinking, contributes to the formation of a physical picture of the world, understanding of the phenomena and patterns that describe these phenomena. Solving problems in physics forms and develops such personal qualities as dedication, perseverance, motivation - interest in science, mathematical and physical abilities. The assimilation of the theoretical material presented at the lecture occurs through the students' independent study of the lecture notes and the use of laws, formulas, graphical dependencies of quantities, values of constants and reference values of physical parameters when solving prob- lems in practical classes and through experimental verification of laws in laboratory classes.

The solution of physical problems (PP) with the help of computer technology is faced with the following methodological and didactic problems [4]:

1) the lack of systematization of the psychological characteristics of the levels of thinking when solving problems;

2) there is no correspondence between the types of tasks being solved and the level of thinking of trainees;

3 ) the connection between the methods of solving problems and the methods of physics are not considered;

4) there is no theoretical justification for the need to use a computer as a modern tool for solving problems in order to master new methods of physics, and correspondence with the procedure;

5) computer methods for solving problems are not systematized;

6) the circle of PPs that can be solved with the help of a computer is not outlined; 
7) the possibilities of developing the creative ability of the student when solving the PP with the help of a computer are not considered.

Solving problems in physics implies the presence of an elementary mathematical base, which is rapidly decreasing every year. So, if in 2011 teachers - mathematicians spoke about ignorance of the Pythagorean theorem $75 \%$ of high school graduates [5], then in 2018 already $90 \%$ cannot even formulate it, that is, the growth of undereducated school graduates is about $2 \%$ per year. And if the Pythagorean theorem is not so often encountered when solving physical problems, then the ability to solve proportions is required in almost every problem. 1-2 students from a group of 30 people can express, for example, $a$ from the expression $a / b=c / d$. Fractions ([6]: $48 \%$ of those who passed the ZNO in mathematics in 2018 did not find the correct answer in the division test $(2 \mathrm{a}+2) / 2=$ ?), Degrees, trigonometric functions and equations, logarithms, derivatives and integrals, quadratic equations, finding the area and volume and further on all items of school mathematics - this is a list of what a modern student does not know. Inability to convert multiples of quantities to SI units: centimeters to meters, grams to kilograms, $\mathrm{GHz}$ to $\mathrm{Hz}$, etc. Knowledge of the dimensions of physical quantities is at the level of knowledge of the Pythagorean theorem, $10-15 \%$ [7].

It is required to conduct training in a language understandable to linkers, i.e. mass attraction of computer, tablet smartphone content, transfer of classes to the network. The author's experience shows the possibility of such training with the help of a site with teaching materials in physics [8], which has more than a million visitors per semester and, accordingly, more than 2 million per year, and in terms of views - more than 5 million per year. The site has been operating for more than 8 years and today has more than 17 million visitors (35 million views), which indicates the demand for accessible teaching material in physics and the need to use new modern approaches in its presentation.

\section{Literary review}

Further, speaking about a computer, we will mean computer equipment: computer, laptop, tablet and smartphones. A computer, as a component of e-learning, has basic didactic principles in common with it [9]: visualization of learning, distribution of educational material in a computer or network, interactivity, individuality in acquiring knowledge, adaptability to personal needs. Let us determine the role a computer can play in solving problems when three cases are possible: solving physical problems on a computer, using a computer, by a computer (a solver program). The use of a computer implies the following applications:

1) a source of information, an electronic textbook, a reference book, a repository of all kinds of data, related to the subject, including examples of problem solving.

2) animation, an interactive model of the problem under consideration.

3) a template with a statement of the problem and a place for entering an answer - simplifies verification, differs from a regular problem book only in an interactive response field.
4) the problem is solved analytically in the traditional way in a notebook, a working formula is found, according to which the desired value is calculated on a computer, i.e. the computer is used as a calculator. In this case, various spread sheet programs, such as Excel, are often used, but this does not change the essence.

5) After obtaining the working formula, a program is drawn up [10], for example, in Qbasic 1.0, Borland Pascal 7.0 or Free Pascal, and an educational computational experiment is carried out, in which a change in the parameters of the system under study, the value and type of external influence, initial conditions makes it possible to analyze the behavior of the desired value, considered in the task, "response" or to investigate the process. This method of using a computer involves writing a calculation program according to a working formula and is more likely suitable for classes in computer science or programming, computer modeling, and can be considered as the topic of a term paper or thesis with programming elements in specialized universities. We do not consider this case as possible for practical use in most technical universities.

6) Using a computer-training program for solving problems [11]. The solution of the problem in the program is divided into 4 main stages: analysis of the problem condition; the choice of the course of solving the problem; drawing up a system of equations, describing the considered phenomenon, state; direct solution - transformation of the resulting system of equations and calculation of the required values. Each of the stages of the solution is accompanied by a series of questions and instructions. Note that, in general, the methodically correctly chosen way of explaining the solution of the problem is burdened with distracting questions: those explaining the solution of the problem, paying attention to the key points and methods of solving, theoretical questions that require knowledge of theory and the ability to perform the simplest actions (find vector projections, add vectors, etc.), and also control questions and a large amount of design work turn the solution of a simple problem into a course project.

7) In addition to solving the problem, it is important to assess the knowledge, gained by students in the course of solving it. To do this, it is necessary to organize a testing system, preferably with different variations of questions, all kinds of inclusion schemes, and the layout of the task elements. Such development of tests will be especially relevant for remote control in online learning mode. The authors [12-14] propose a methodology for solving the problem of analysis, modeling and practical implementation of a test block to test physical knowledge, the ability to solve PP from a specific section of physics in distance learning, using the technology of adaptive and template tests that comply with IMS and SCORM standards. A formal model of a physical process, a test generation method, and a change in the level of complexity are proposed.

Discussion of solving problems in physics using ICT and a computer, as one of the elements of this technology, is the topic of numerous publications by domestic and foreign researchers. The authors of [15] name twelve types of physical problems that can be solved using a computer. Let's enumerate these types, adding to 
each type a possible software product, on which it can be implemented. But first, let's make a note that the currently existing systems of computer mathematics, such as MathLab, Mathematica, Maple, partially MathCad, can solve all types of physical problems and therefore we do not name them below, meaning their versatility:

1) Problems of the "calculator" type. A built-in computer or smartphone calculator is enough. Online programs, applications for smartphones with a set of formulas - Mobile Physics, Physics, PhysicsHelper +, etc. Rather, they are physics reference books than problem solvers. Physical calculators, designed for mathematical calculations of the required value by the entered variables, for example, Byju's Physical Calculator [16], OMNI' calculator (physics calculators) [17], Physics 101 SE [18], contains more than 150 equalities from 23 branches of physics. The programs can be useful for schoolchildren and students to consolidate the basic concepts: what is the distance, traveled by the body for a certain interval with uniformly accelerated motion with a given initial speed and acceleration, etc. An ordinary calculator is able to do the same thing as the socalled physical, provided that the corresponding formulas are known. The need to use a physical calculator arises when you need to quickly calculate something without being interested in the physics of the process. This section includes numerous programs and systems of computer algebra, listed above, and used as advanced calculators.

2) Graphics tasks - a variety of graphing programs, preference is given to the appropriate computer operating system. These can be Excel (Microsoft), Graph (SPbU Software), Origin (OriginLab Corporation), Grapher (Golden Software, Inc.), SigmaPlot (Systat Software Inc.), Desmos (Desmos Inc.), etc.

3) problems for solving transcendental, trigonometric, logarithmic, power equations - Microsoft Math Solver, Photomath (Microblink).

4) Problems for solving systems of equations: Maxima (MIT), STACK - System for Teaching and Assessment using a Computer algebra Kernel uses the computer algebra system (CAS) Maxima. In the following paragraphs 5-10, you can use one or several programs from the list [19].

5) Tasks for finding extremes.

6) Optimization tasks.

7) Problems of differential type.

8) Problems of integral type.

9) Calculating tasks.

10) Problems of mixed type.

In paragraphs 11-12, the task of developing models, physical modeling, creating virtual laboratory works is today solved using packages of mathematical, physical, technical modeling. There are hundreds of computer simulation programs [20]. In particular, we used in [2123] - LabVIEW National Instruments + Multisim, Wolfram Mathematica + SystemModeler, MATLAB + Simulink, Maple + MapleSim. Modelica, COMSOL Multiphysics Interactive Physics, Open Physics 2.6 are also widely used in the educational process.

11) Tasks for modeling physical processes.

12) Tasks for simulation of physical processes pseudo-simulation.
Separately, we will highlight the rapidly developing programs using elements of artificial intelligence, developed both on classical CAS and new software solutions: betaphysics (Group 747), MapleCalculator, Symbolab - Math solver (Symbolab).

The above analysis of the use of a computer in solving various types of problems shows the absence of programs that would allow a student to solve problems independently in the usual form and order of actions, by writing a condition, translating data into SI, solving using the necessary formulas, deriving a design equation, substituting data, receiving an answer in symbolic or numerical form, checking the dimension. The development and use of such a program seems to be an urgent problem at the present stage of physical education in higher education.

\section{The aim and objectives of research}

The purpose of this work is to develop an automatic solver of physical problems APS and to study the possibility of using it in practical classes in physics.

To achieve the goal, it is necessary to solve the following tasks:

1. Give a detailed description of the APS program, the sequence of work in it when solving problems, compare the solution, performed with the program, with the traditional "manual" one on the board or in a notebook.

2. Consider the didactic goals of using the computer solution of physical problems. Show that the use of a computer allows students to work in a digital environment familiar to them, to find a solution to a problem by choosing suitable formulas, dependencies, patterns by the method of descent from the general to the particular, as is done with a "manual" solution.

3. To analyze the advantages of the computer solution of physical problems, to show that the computerization of problem solving contributes to the filling of the virtual educational environment.

\section{Materials and methods}

In the process of scientific research, the following methods were used: analysis and systematization - when reviewing scientific articles, reports of scientific conferences, teaching aids, which present developments, reviews, descriptions of issues that relate to methods for solving physical problems. The comparative analysis was used method when considering traditional and computer methods for solving problems; synthesis, comparison, systematization, generalization - while obtaining and discussing the results and formulating the conclusions of the work.

\section{Research and discussion results}

One of the problems that higher education teachers face is the inverse relationship between learners' knowledge and ICT. The decline from year to year in the average level of mathematical and physical training of applicants requires the teacher to search for new methodological approaches to the pedagogical process. Known modern pedagogical technologies, the classification of which includes more than 30 types [24]. ICT is a type of pedagogical technologies, which today include such as "Advanced Education Technology" or the 
theory of inventive problem solving (TIPS), education technology in the global information community (ETGIC), cooperation pedagogy or "learning in cooperation" (LIC), art pedagogy.

The use of computer technologies makes it possible to solve the problems of motivated involvement of students in the educational process, improving the quality of education, increasing subject competences, practical skills, forming personal characteristics and communicative abilities of students.

It is known [25], that for didactic purposes, pedagogical software tools are divided into groups for:

1) actualizing knowledge;

2) the formation of knowledge, abilities, skills;

3) consolidation of knowledge, abilities, skills;

4) control of knowledge;

5) generalization and systematization knowledge;

6) improving knowledge.

Teaching a student to solve problems implies instilling certain skills and abilities, learning and memorizing certain algorithms for solving problems. The complexity in solving the PP can be explained, among other things, by a large number (about 20) of different algorithms and techniques. Moreover, if it is possible to single out general steps, an algorithm for solving a large number of PPs, which includes 10 points, actions, then when solving problems of a specific section: kinematics, dynamics of translational and rotational motion, molecular physics and thermodynamics ... nuclear physics, it is necessary to use the solution technique, defined for this section. The process of learning to solve typical PPs, not to mention some more complex PPs, is reduced to memorizing, understanding and applying the corresponding algorithms - methods. At the same time, cognitive problems arise when a student perceives the solution of a problem as reducing it to an appropriate algorithm, although the teacher, as a rule, talks about the principles, concepts, laws of the solution, but in the end it all comes down to a set of equalities, a system of equations. And students have a false idea that writing equations and working with them lead to an answer, while the cognitive, educational part of the task is lost.

Of particular unease and preoccupation is the solution of elementary PPs, when you often come across a situation that in the example, solved on the blackboard, the numerical change in the conditions of the problem causes stupor among students. For example, the problem No. 18.1 from [26], solved and left on the board as an example. Next, for an independent solution, the condition of the problem No. 18.4 is written, which differs only in the numerical value of the quantities. But $20-30 \%$ cannot solve by example, without delving into the essence of the problem, without doing anything that is suggested by methods and algorithms for solving. Moreover, this percentage of undecided does not depend on the socio- economic formation, state structure, the level of economic development of the country and other factors.

In modern and classical problem books for the general course of physics for technical universities, the problems are selected in such a way that, as a rule, they require a quantitative calculation in an analytical solution using a number of formulas or graphical dependencies. For the initial acquisition of solution skills, simple problems are considered, and taking into account the fact that many physical laws are written in the simplest form through three symbols, many problems are elementary. This can explain the well-deserved popularity of V. S. Volkenshteyn [26], the first edition of which was in 1959 and has been republished more than 20 times to this day.

To create a PP solution, which would meet the cognitive, pedagogical, methodological, substantive requirements for practical lessons in physics, an APS application package was developed that works in the computer algebra system Wolfram Mathematica 11.2 and higher.

It is known [27-29], that algorithms for solving problems in physics include about ten items. This is an analysis of the condition of the problem and its correlation to a specific section, and then to a subsection of physics. Write down the condition and convert the units to SI. If necessary, then make a drawing for the problem, on which to show forces, accelerations, speeds or other quantities. When solving problems with electrical circuits, it is necessary to arrange currents, voltages, select contours, set the directions of their bypass. Comparing the data in the condition of the problem and the wellknown formulas, the laws of a previously defined section of physics, determine from which ratios it is possible to express the desired value, given in the condition of the problem. Write down the calculation formula for finding the unknown through the given in the condition. Check the conformity of the dimensions according to the working formula. Find the numerical value of the required quantity. Analyze the received answer.

The stage of comparison, application of wellknown laws, formulas, relations of physics for the mathematical recording of the conditions of the problem, drawing up a system of equations for finding the desired value according to V. A. Balash [27], is the most difficult and poorly understood by students. The transition from the physics of a problem to its mathematical description presents the main difficulty in solving most physical problems.

The developed APS package allows, by parsing the text, to write the condition of the problem with automatic data translation into SI, by choosing from the proposed set of formulas to come to a working formula and using it to programmatically check the dimension of the desired value. Make numerical calculations and get an answer. A fragment of the package operation is shown in Fig. 1. 


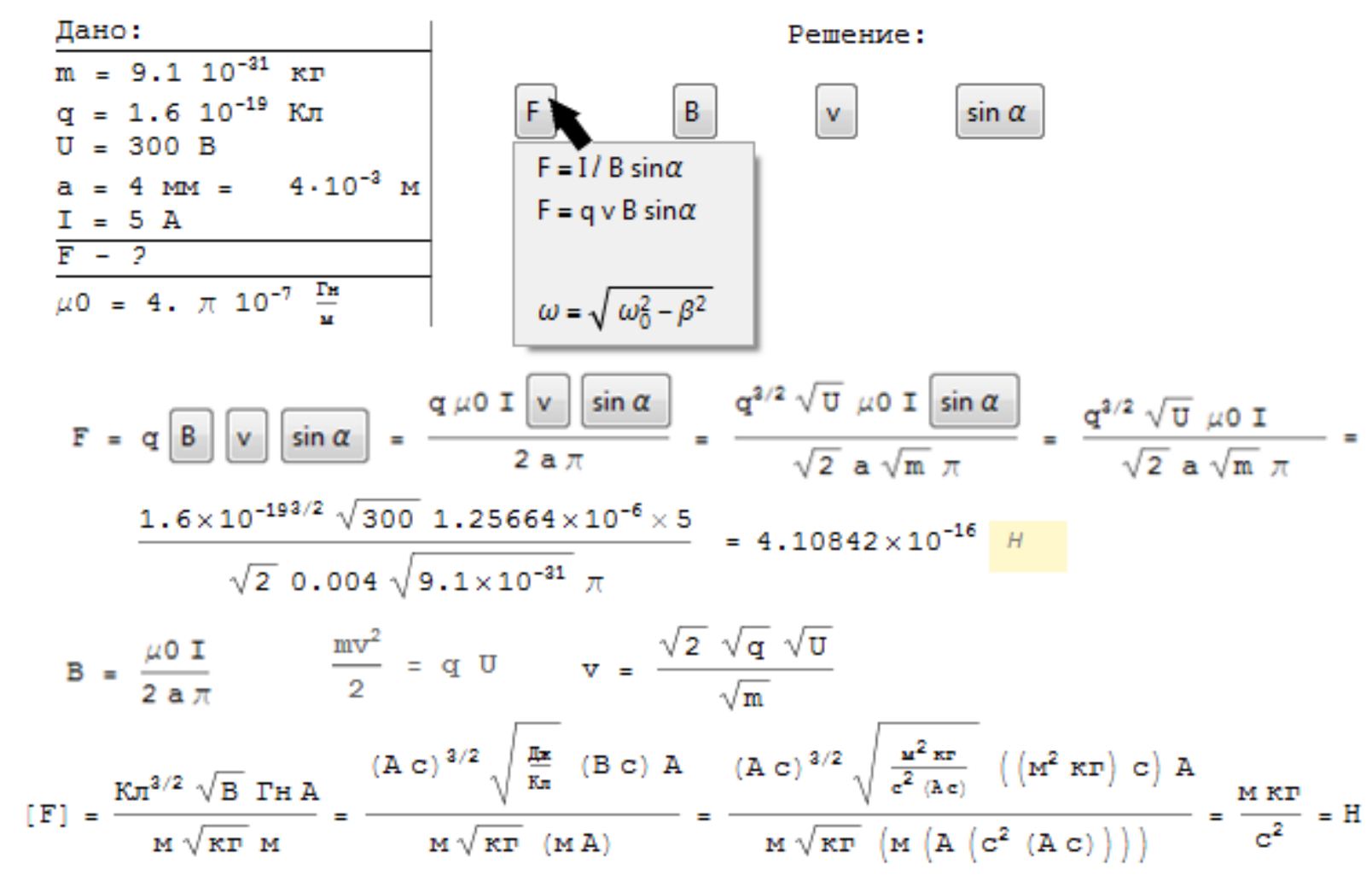

Fig. 1. An example of solving a problem using the APS program

The algorithm for solving problems in APS is similar to that, used for "manual" solution. Step-by-step cutoff, descent from a more general, high section, to a particular, low level. So for the example under consideration in the section "Electromagnetism" the program of the pallet of the force formulas is selected by the program of the pallet: "Ampere force, Lorentz force, Newton's second law", etc. When choosing any force, after clicking on its expression in the pallet, this formula is duplicated in the solution field. Values, included in the formula, the numerical value of which is not known, will be displayed as active buttons. Pressing these buttons leads to the opening of the corresponding pallet. For example, pressing the magnetic induction button $\boldsymbol{B}$ in the figure will open a pallet, containing the expression for the magnetic induction of a straight infinitely long conductor, the field of a conductor of finite length, and a circular current field. The choice of any field leads to the "substitution" of the corresponding expression in the expression of the Lorentz force. Then the substitution of the velocity, obtained from the law of conservation of energy by the solution with respect to $v$ and the sine of the angle, is made. If a working formula is obtained, then the substitution of numerical values that the program performs will give the answer to the problem. If at some step of the solution the wrong formula or value of the quantity is chosen, then using the clear buttons (not shown in the figure) $\boldsymbol{B}, v$, $\sin \alpha, \boldsymbol{F}$ they can be removed from the solution. Dimension checking is also performed by the program, and, as you can see in the figure, in this example it is a nontrivial task that takes quite a long time with a usual solution, and therefore is often not carried out. The problem is solved until the correct answer, written in the program, is obtained. To check the assimilation of the material, the solution of several similar problems is proposed. Controlling the progress of their solution, the number of steps, returning to the previous steps, the time of the solution allows revealing the understanding of the solution of this class of problems, the development of skills.

Note that a large volume of Wolfram Player ( 987 Mbyte) and a cdf file give a heavy load on the site, the provider blocks the site. Because of this, it was necessary to abandon the placement of a large number of interactive problem solutions, and use the APS program on stationary devices. Perhaps using the Wolfram Cloud will allow you to work online.

The use of a computer solver of physical problems allows one to overcome a number of disadvantages inherent in the traditional "manual" solution. First of all, the absence of an elementary mathematical basis causes a psychological stupor, self-doubt, in their actions when solving the simplest physical problems. Poor training in physics leads to the fact that the student cannot begin to solve, analyze and write down a short condition of the problem using these quantities, because he/she does not know their designations. The traditional way of teaching problem solving involves the teacher explaining the solution of 1-2 problems, as an example of the application of the corresponding algorithm, and the subsequent independent solution of such problems. The use of the principle "from the particular to the general" has a drawback, associated with the difficulty of independent selection of methods and techniques for solving a specific problem. Problem solving skills appear when solving a large number of problems, generalized knowledge is formed with experience, in the process of problem solving [30]. APS 
allows you to consider examples of solving a fairly large number of problems for each branch of physics.

The problem of choosing the necessary formulas, laws, the fear of going down the wrong path of solution, is another obstacle for unprepared students. The considered solver does not limit the number of attempts to find the correct solution.

The authors of [31], when comparing the methods of solving the traditional method and using computer simulation, list ten advantages of modeling that are inherent in APS. In addition, let us highlight its main difference - it really teaches students to solve physical problems.

We also note that a huge variety of physical problems and their solution methods is unlikely to create a single universal solver for all branches of physics.

Therefore, the considered automatic problem solver is intended primarily as a means of teaching the solution of typical PP, expanding the number of tasks to be solved, learning "by example". APS does not replace the teacher, but is his/her didactic assistant.

Further research in the development of APS will be associated with expanding the range of problems it solves, developing a mobile version of the solver with subsequent placement on the Google Play and App
Store platforms for distributing the program in the educational teaching and student environment.

\section{Conclusions}

1. The presence of objective prerequisites for finding ways to improve the qualifications (ability) of students to effectively use examples of solving problems in the educational process, in particular, to overcome psychological barriers, such as fear, anxiety, self-doubt, confusion in front of the changing conditions of the problem is revealed.

2. The methodology (algorithmization) of learning the PP solution, which includes ten steps, is considered as a general. Its implementation helped to activate the creative and cognitive activity of students, to form their ability to process and analyze the information, contained in the problem statement; the ability to translate it into the mathematical language of the condition of the problem, to differentiate problems by sections of physics, using the formula baggage of the corresponding section to find a solution to the problem.

3. The key components of the developed program for the automatic solution of PP, the possibility of creating an electronic training course on its basis, the principles and didactic functions of the course being developed are considered.

\section{References}

1. Losev, A. F. (1988). Derzanie dukha. Moscow: Sovetskii pisatel, 210.

2. Tikhomirova, S. A. (2003). Didakticheskie materialy po fizike, 7-11 klassy. Moscow: Shk. Pressa, 106.

3. Zenkina, S., Suvorova, T., Pankratova, O., Filimanyuk, L. (2019). The Method of Design of Electronic Advanced Training Courses for the Development of Information Competence of the Teacher. Proceedings of SLET-2019 - International Scientific Conference Innovative Approaches to the Application of Digital Technologies in Education and Research. Stavropol - Dombay, 366375. Available at: http://ceur-ws.org/Vol-2494/paper_35.pdf

4. Petrosian, V. G. (2009). Reshenie fizicheskikh zadach s pomoschiu kompiutera kak sostavliaiuschaia fizicheskogo obrazovaniia. Nalchik, 482

5. Zeleniak, O. P. (2012). Modeliuvannia dynamichnoi heometrychnoi konfihuratsii. Kompiuter u shkoli ta simi, 4, 33-40. Available at: http://nbuv.gov.ua/UJRN/komp_2012_4_13

6. Bakhrushyn, V. (2018). Yakist serednoi osvity: pro shcho svidchat rezultaty ZNO. Available at: https://nus.org.ua/view/yakist-serednoyi-osvity-pro-shho-svidchat-rezultaty-zno/

7. Kylmukhametova, N. T. (2012). Preodolenye matematycheskykh zatrudnenyi pry reshenyy zadach po fyzyke. Sterlytamak. Available at: http://npopy54.narod.ru/download/fizika.docx

8. Shamshin, A. P. Physics Teaching Materials. Available at: http://bog5.in.ua

9. Solovova, N. V., Dmitriev, D. S., Sukhankina, N. V., Dmitrieva, D. S. (2020). TSifrovaia pedagogika: tekhnologii i metody. Samara: Izd-vo Samarskogo un-ta, 128.

10. Maier, R. V. (2012). Zadachi, algoritmy, programmy. Glazov: Glazovsk. gos. ped. in-t. Available at: http://maierrv.glazov.net

11. Berdennikova, M. G. (2010). Reshenie zadach po fizike s ispolzovaniem kompiuternoi programmy: metod, ukazaniia $\mathrm{k}$ samostoiatelnoi rabote. Arkhangelsk: SAFU, 16.

12. Lvov, M., Kuzmenkov, S., Kravtsov, H. (2019). About One Approach to Building Systems for Testing Physical Knowledge. CEUR Workshop Proceedings, 2393, 1-16.

13. Lvov, M., Kuzmenkov, S., Kravtsov, H. (2020). System for Testing Physics Knowledge. International Conference on Information and Communication Technologies in Education, Research, and Industrial Applications. Communications in Computer and Information Science, CCIS, 1175, 186-209. doi: http://doi.org/10.1007/978-3-030-39459-2_9

14. Kravtsov, H. (2009). Evaluation Metrics of Electronic Learning Resources Quality. Information Technologies in Education, 3, 141-147. doi: http://doi.org/10.14308/ite000065

15. Petrosian, V. G., Likhitskaia, I. V., Beitokova, L. R., Gazarian, R. M. (2003). Reshenie fizicheskikh zadach s pomoschiu kompiutera. Nalchik: Kab.-Balk. un-t, 256.

16. BYJU'S Online Calculator. Available at: https://byjus.com/physics-calculators/

17. Physics calculators. Omni calculator. Available at: https://www.omnicalculator.com/physics

18. The formulas of Physics 101SE. Praeter Sofware. Available at: http://www.praetersoftware.com/products/ physics101/formula.html\#list

19. Top 30 Best Free Math software you can use (2019). Available at: https://thegeekpage.com/best-free-math-softwares/

20. List of computer simulation software. Available at: http://en.wikipedia.org/wiki/List_of_computer_simulation_software

21. Shamshin, A. P. (2012). Kompyuterniy laboratorniy praktikum po magnetizmu, kolebaniyam i mekhanike s ispolzovaniem LabVIEW, MATLAB i Word. Inzhenernoe i nauchnoe prilozheniya na baze tekhnologiy National Instruments. Moscow, 195-197. 
22. Shamshin, O. P. (2016). Laboratorni roboty z vykorystanniam smartfonu u fizychnomu praktykumi. Novitni kompiuterni tekhnolohii, 14, 131-132.

23. Shamshin, O. P. (2017). Dystantsiini laboratorni roboty u fizychnomu praktykumi. Novitni kompiuterni tekhnolohii, 15, $185-188$

24. Selevko, G. K. (1998). Sovremennye obrazovatelnye tekhnologii. Moscow: Narodnoe obrazovanie, 256.

25. Pegov, A. A., Pianykh, E. G. (2010). Ispolzovanie sovremennykh informatsionnykh i kommunikatsionnykh tekhnologii v uchebnom protsesse. Available at: https://www.tspu.edu.ru/images/faculties/fmf/files/UMK/lek.pdf

26. Volkenshtein, V. S. (1985). Sbornik zadach po obschemu kursu fiziki. Moscow: Nauka, 384.

27. Balash, V. A. (1983). Zadachi po fizike i metody ikh resheniia. Moscow: Prosveschenie, 434.

28. Igropulo, V. S., Viaznikov, N. V. (2000). Fizika: algoritmy, zadachi, resheniia. Moscow: Ileksa, Stavropol: Servisshkola, 592.

29. Pol, H., Harskamp, E., Suhre, C. (2005). Solving physics problems with the help of computer- assisted instruction. International Journal of Science Education, 27 (4), 451-469. doi: http://doi.org/10.1080/0950069042000266164

30. Savchenko, E. V. (2020). Usage of basic problem-solving techniques in the discipline of general physics in higher school. Sovremennoe Obrazovanie, 3, 34-48. doi: http://doi.org/10.25136/2409-8736.2020.3.31599

31. Dmitriev, V. M., Filippov, A. Iu., Gandzha, T. V., Dmitriev, I. V. (2010). Kompiuternoe modelirovanie fizicheskikh zadach. Tomsk: V-Spektr, 248.

Received date 10.08.2021

Accepted date 21.09.2021

Published date 30.09.2021

Alexandr Shamshin, PhD, Assistant Professor, Department of Fundamental Disciplines, National Academy of National Guard of Ukraine, Zakhysnykiv Ukrainy sq., 3, Kharkiv, Ukraine, 61001

E-mail: apshamshin@gmail.com 